\title{
Baicalin Augments Hyperthermia-Induced Apoptosis in U937 Cells and Modulates the MAPK Pathway via ROS Generation
}

\author{
Shahbaz Ahmad Zakki Zheng-Guo Cui Lu Sun Qian-Wen Feng Meng-Ling Li \\ Hidekuni Inadera
}

Department of Public Health, Graduate School of Medicine and Pharmaceutical Sciences, University of Toyama, Toyama, Japan

\section{Key Words}

Hyperthermia • Baicalin • Anticancer • Apoptosis • ROS • MAPK

\begin{abstract}
Background/Aims: Hyperthermia is a widely used therapeutic tool for cancer therapy and a well-known inducer of apoptosis. Although the flavonoid compound baicalin (BCN) is a potent anticancer agent for several human carcinomas, it is less potent in the human U937 myelomonocytic leukemia cell line. To explore any enhancing effects of $\mathrm{BCN}$ on hyperthermiainduced apoptosis, this study investigated the combined effects and apoptotic mechanisms of hyperthermia and BCN in U937 cells. Methods: U937 cells were heat treated at $44^{\circ} \mathrm{C}$ for 12 min with or without pre-treatment with $B C N(10-50 \mu \mathrm{M})$ and then incubated for $6 \mathrm{~h}$ at $37{ }^{\circ} \mathrm{C}$ with $5 \% \mathrm{CO}_{2}$ and $95 \%$ air. Cell viability was analyzed by Trypan blue exclusion assay. Apoptosis was examined by DNA fragmentation, fluorescence microscopy and flow cytometry. Generation of mitochondrial trans-membrane potential (MMP), mitochondrial calcium, and reactive oxygen species (ROS) was also detected by flow cytometry. The expression of proteins related to apoptosis and signaling pathways was determined by western blotting. Results: Hyperthermia alone did not reduce cell viability or induce notable levels of apoptosis, but combined hyperthermia and $\mathrm{BCN}$ treatment markedly augmented apoptosis by upregulating proapoptotic proteins and suppressing antiapoptotic proteins, culminating in caspase- 3 activation. Mitochondrial transmembrane potential was significantly decreased, and generation of reactive oxygen species (ROS) and suppression of antioxidant enzymes were marked. Furthermore, with the combined treatment, the phosphorylated forms of JNK and p38 showed increased expression, whereas AKT was dephosphorylated. JNK-IN-8 (a JNK inhibitor) and NAC (a ROS scavenger) abrogated the apoptotic effects of the combined treatment, significantly protecting the cells and indicating the involvement of high ROS generation and the MAPK pathway in the underlying molecular mechanism. Conclusion: This study provides compelling evidence that hyperthermia, in combination with $\mathrm{BCN}$, is a promising therapeutic strategy for enhancement of apoptosis and suggest a promising therapeutic approach for cancer.




\section{Cellular Physiology Cell Physiol Biochem 2018;45:2444-2460 \\ and Biochemistry Published online: March 19, $2018 \quad \begin{aligned} & \text { DOI: 10.1159/000488263 } 2018 \text { The Author(s). Published by S. Karger AG, Basel } \\ & \text { www.karger.com/cpb }\end{aligned}$ \\ Zakki et al.: Baicalin Augments Hyperthermia-Induced Apoptosis}

\section{Introduction}

Hyperthermia (HT) or heat treatment has been used for at least 5000 years as anticancer therapy. Recent advances in HT techniques, such as noninvasive thermometry, computer modeling, and nanotechnology, have had a considerable impact on cancer treatment. Tumor cells are more sensitive to HT than normal cells, but its effectiveness depends on the temperature and duration. Generally, normal tissues, excluding nerve tissues, are not damaged by $1 \mathrm{~h}$ treatment of HT up to $44^{\circ} \mathrm{C}$. HT is a well-known inducer of apoptosis, but the degree of apoptosis and apoptotic pathway involved depend on the nature of the cell line examined. Although clinical studies of HT alone provide somewhat satisfactory results, $\mathrm{HT}$ alone is insufficient to completely kill tumor cells and an additional agent is required to overcome these limitations [1-3].

Scutellaria baicalensis Georgi (Japanese, Wong or Ogan; Chinese, Huang Qin; English, Baikal skullcap or skullcap) is a perennial herb belonging to the Lamiaceae family that is cultivated in Japan, China, Korea, Mongolia, and the Russian Federation [4]. It is classified as a "middle-grade" herb in the Chinese medical classic "Shennong's herba" [5]. Its dried root contains over 30 kinds of flavonoids, mainly baicalin (BCN), baicalein, wogonoside, wogonin, oroxylin A, and oroxylin A-7. These compounds contribute to its ability to induce apoptosis and inhibit proliferation in different cancer cells [6,7]. BCN is a 5, 6-dihydroxy7-o-glucuronide flavone [8], whereas baicalein is a 5, 6,7-trihydroxyflavone, but about $90 \%$ of administered baicalein is metabolized to BCN [9]. Previous flavone studies revealed that BCN, also a component of Sho-Saiko-to [10], has multiple biological properties, including anti-inflammatory, antimicrobial, antiviral, antioxidant, and protective effects against various tissue and organ damage. In the K562 cell line, BCN inhibits erythroid differentiation and reduces colony formation [4]. In addition, it also possesses some beneficial effects in disease models such as those of hepatic toxicity, hypoxia/reoxygenation-induced cardiac muscle injury, and rheumatoid arthritis and in iron-overloaded mice [9]. In addition, BCN also exhibits anticancer effects for several cancers such as colon cancer, breast cancer, Burkitt lymphoma, cervical cancer [11], lung cancer, prostate cancer, hepatic cancer, ovarian cancer, and pancreatic cancer $[4,8]$. However, the exact underlying mechanisms remain unclear.

Apoptosis, or type 1 programmed cell death, is a significant terminal pathway in multicellular organisms and is responsible for cellular biological events such as maintenance of homeostasis, development, differentiation, and elimination of harmful cells. Furthermore, it is distinct from other types of cell death based on its incidence, biochemistry, and morphology. In contrast, aberrant apoptosis is fundamental to carcinogenesis, tumor progression, and development of anticancer drug resistance. Consequently, apoptosis is considered to be a primary target for drug discovery and development, particularly for cancer treatment. In mammals, there are two major apoptotic pathways resulting in caspase activation: the extrinsic or death receptor-mediated pathway and the intrinsic or mitochondrial-mediated pathway. In addition, there is another less well-known endoplasmic reticulum (ER) stress-mediated pathway for caspase activation [12]. In the intrinsic signaling pathway, the proapoptotic protein Bid regulates the translocation of proapoptotic Bax to the mitochondrial membrane. The ratio of endogenous pro- to antiapoptotic proteins is the determinant of life and death [13].

BCN arrests mouse leukemia cell proliferation in in vivo studies [14], as well as in vitro [15], and complete inhibition of acute lymphatic leukemia, myeloma, and lymphoma cell lines has also been found [15]. In addition, BCN possesses cytotoxic effects in the U937 cell line $[10,16]$. However, the significant effect was attributed to either too high a concentration of BCN or too long an exposure. The U937 cell line is widely used to investigate the mechanisms involved in apoptosis [17]. As discussed in previous studies, BCN has promising effects as an adjunct to cancer therapy [18]. Thus, in the present study, we used BCN as an adjunctive therapy to HT to induce apoptosis and ultimately develop a promising anticancer therapy. We also explored the molecular mechanisms involved. 


\section{Cellular Physiology Cell Physiol Biochem 2018;45:2444-2460

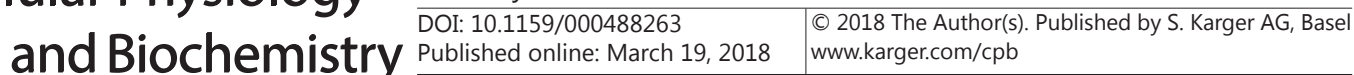 \\ Zakki et al.: Baicalin Augments Hyperthermia-Induced Apoptosis}

\section{Materials and Methods}

\section{Chemicals}

BCN (product number, B2835; lot, 63BCA) and BAPTA-AM [1, 2-Bis (2-aminophenoxy) ethane- $N, N, N^{\prime}, N^{\prime}$ tetraacetic acid tetrakis (acetoxymethyl ester)] were purchased from Tokyo Chemical Industry, Japan. Trypan blue stain was purchased from ICN Biomedicals, Inc. (Aurora, OH). JNK-IN-8 was obtained from EMB Chemical, Inc. (San Diego, CA), Hoechst stain 33258 dye, N-acetyl-cysteine, and tauroursodeoxycholic acid (Tudca) were purchased from Sigma Aldrich (St. Louis, MO).

\section{Cell culture and treatment}

The human myelomonocytic lymphoma U937 cell line was purchased from Human Science Research Resources Bank Japan (Japan Human Sciences Foundation, Tokyo, Japan). U937 cells were grown in RPMI-1640 medium containing 10\% heat-inactivated fetal bovine serum and maintained in a humidified incubator at $37^{\circ} \mathrm{C}$ with $5 \% \mathrm{CO}_{2}$ and $95 \%$ air, as reported previously [19]. For HT, U937 cells were seeded in $15-\mathrm{mL}$ plastic tubes at a density of $2 \times 10^{6}$ cells suspended in $4 \mathrm{~mL}$ of media, followed by immersion in a temperature-controlled water bath at $37^{\circ} \mathrm{C}$ or $44^{\circ} \mathrm{C}$ for $12 \mathrm{~min}$, preceded by $3 \mathrm{~min}$ to warm the samples up to the desired temperature. BCN at the indicated concentrations was added to the samples $30 \mathrm{~min}$ before HT as a pretreatment [19].

\section{Hoechst staining}

The cells were harvested, washed with Dulbecco's phosphate-buffered saline (PBS) (Nissui Pharmaceuticals Co. Ltd., Tokyo, Japan), and collected by centrifugation. They were then fixed with $4 \%$ paraformaldehyde in PBS for $30 \mathrm{~min}$ at $4^{\circ} \mathrm{C}$ and stained with $1 \mathrm{mM}$ Hoechst stain 33258 for $15 \mathrm{~min}$. Cell body shrinkage, nuclear condensation, and apoptotic bodies were visualized and captured by a fluorescence microscope (BX-61, Olympus, Tokyo, Japan) at 400× magnification.

\section{Trypan blue exclusion assay}

Cell viability was determined by a Trypan blue exclusion assay by using a Burker counting chamber after Trypan blue staining ( $0.4 \%, 1: 3$ dilution in the cell-containing culture medium), as reported previously [20]. Briefly, U937 cells were seeded in 6-cm dishes at a density of $2 \times 10^{6}$ cells and subsequently treated with BCN and HT. After $6 \mathrm{~h}$ and $24 \mathrm{~h}$ of post-treatment incubation, cells were harvested, stained, and counted.

\section{Assessment of DNA fragmentation}

A quantitative DNA fragmentation assay was carried out following the method of Sellins and Cohen [21], with minor modifications. Briefly, the cells were harvested after $6 \mathrm{~h}$ of treatment and lysed with 200 $\mu \mathrm{L}$ of lysis buffer (10 mM Tris, $1 \mathrm{mM}$ EDTA, and 0.1\% NP-40, pH 7.5), followed by centrifugation at 13, $000 \times \mathrm{g}$ for $10 \mathrm{~min}$ to separate intact from fragmented chromatin, and transferred into separate tubes. The fragmented DNA in the supernatant and intact DNA in the pellet were precipitated overnight at $4^{\circ} \mathrm{C}$ in $12.5 \%$ trichloroacetic acid. DNA precipitates were hydrolyzed by heating at $90^{\circ} \mathrm{C}$ for $20 \mathrm{~min}$ in $5 \%$ trichloroacetic acid. For quantification of fragmented DNA, after overnight color development (Beckman DU-50) with diphenylamine (DPA) reagent ( $0.15 \mathrm{~g}$ DPA, $0.15 \mathrm{~mL} \mathrm{H}_{2} \mathrm{SO}_{4}$, and $0.05 \mathrm{~mL}$ acetaldehyde $/ 10 \mathrm{~mL}$ glacial acetic acid), the absorbance was measured at $600 \mathrm{~nm}$ by a microplate reader (Multiscan, Thermo Fisher Scientific, Shanghai, China). "Percent fragmentation" refers to the ratio of DNA in the supernatant (fragmented) to the total DNA recovered in both the supernatant and pellet (fragmented plus intact).

\section{Apoptosis detection by flow cytometry}

Flow cytometry was performed with fluorescein isothiocyanate (FITC)-labeled Annexin V and propidium iodide (PI) for the detection of phosphatidylserine externalization on the surface of the cell membrane, used as an end-point indicator of early apoptosis and necrotic cells or late apoptosis, respectively [22]. The cells were harvested, centrifuged at $5000 \times \mathrm{g}$ for $5 \mathrm{~min}$, washed with cold PBS, and finally $490 \mu \mathrm{L}$ of cell suspension was stained with FITC-labeled Annexin V $(5 \mu \mathrm{L})$ and PI $(5 \mu \mathrm{L})$ for $15 \mathrm{~min}$ in the dark. Apoptosis was detected using a flow cytometer (Epics XL, Beckman-Coulter, Miami, FL) following the manufacturer's instructions [23]. 


\section{Cellular Physiology Cell Physiol Biochem 2018;45:2444-2460 and Biochemistry \begin{tabular}{l|l} 
DOI: 10.1159/000488263 & $\begin{array}{l}\text { (O) 2018 The Author(s). Published by S. Karger AG, Basel } \\
\text { www.karger.com/cpb }\end{array}$ \\
\hline Published online: March 19, 2018
\end{tabular}}

Zakki et al.: Baicalin Augments Hyperthermia-Induced Apoptosis

\section{Mitochondrial transmembrane potential}

After HT with or without BCN, performed for $3 \mathrm{~h}$, cells were collected and treated with $10 \mathrm{nM}$ tetramethylrhodamine, methyl ester, and perchlorate (TMRM; Molecular Probes, Eugene, OR) in $1 \mathrm{~mL}$ of 1 $\times$ PBS for $15 \mathrm{~min}$ at $37^{\circ} \mathrm{C}$. TMRM is a cationic fluorophore that is widely used to stain mitochondria and the mitochondrial matrix. The percentage of cells with a low mitochondrial transmembrane potential (MMP) was detected by flow cytometry (BD FACSCanto II Flow Cytometer ver. 1.1 and Diva 6.1, BD Biosciences, Mississauga, Canada), and data were analyzed using Flowing software 2.5.1 (Turku, Finland; http:// flowingsoftware.btk.fi).

\section{Estimation of mitochondrial free calcium}

The calcium probe Rhod 2-AM (Molecular Probes) was used to determine the effect of individual and combined treatments on mitochondrial free calcium homeostasis. Labeled calcium indicators exhibited an increase in fluorescence upon binding to mitochondrial $\mathrm{Ca}^{2+}$. The cells were washed twice with Hank's balanced salt solution (HBSS) and were preloaded with $5 \mu \mathrm{M}$ Rhod 2-AM in HBSS at $37^{\circ} \mathrm{C}$ for $30 \mathrm{~min}$ in the dark, followed by pretreatment with BCN and treatment with HT. After $3 \mathrm{~h}$ of incubation, the cells were harvested, centrifuged at $5000 \times \mathrm{g}$ for $5 \mathrm{~min}$, and washed with HBSS again. Finally, fluorescence was detected by using a flow cytometer (BD FACSCanto II Flow Cytometer ver. 1.1 and Diva 6.1), following the manufacturer's instructions [23], and data were analyzed using Flowing software 2.5.1.

\section{Assessment of intracellular reactive oxygen species}

Intracellular reactive oxygen species (ROS) levels were measured using dihydroethidium (DHE) and 2',7'-dichlorodihydrofluorescein diacetate (DCFH-DA) (Molecular Probes). DHE is oxidized by ROS within the cell to produce ethidium bromide, which fluoresces when it intercalates into DNA. In addition, esterase cleavage of the lipophilic blocking groups of DCFH-DA yields a charged form of the dye, which is oxidized with ROS generation and can be detected by monitoring the increase in fluorescence with a flow cytometer. Briefly, after harvesting, the cells were incubated with $4 \mu \mathrm{M}$ dihydroethidium and $20 \mu \mathrm{M}$ of DCFH-DA separately for $30 \mathrm{~min}$ at $37^{\circ} \mathrm{C}$. After two washes with Dulbecco's PBS, the population of stained cells was measured using a flow cytometer (BD FACSCanto II Flow Cytometer ver. 1.1 and Diva 6.1), and data were analyzed using Flowing software 2.5.1.

\section{Western blot analysis}

Western blot analysis was carried out according to the method described by Cui et al. [19]. Briefly, cells were harvested and washed with PBS and then lysed in RIPA buffer (150 mM NaCl, 1\% Triton X-100 $(\mathrm{v} / \mathrm{v}), 1 \%$ sodium deoxycholate, $0.1 \% \mathrm{SDS}, 1 \mu \mathrm{g} / \mathrm{mL}$ each of aprotinin, pepstatin, and leupeptin, $1 \mathrm{mM}$ EGTA, $50 \mathrm{mM}$ Tris- $\mathrm{HCl}, \mathrm{pH} 7.5$ ) for $20 \mathrm{~min}$ on ice. After brief sonication, the lysates were centrifuged at 13, $000 \times \mathrm{g}$ for $10 \mathrm{~min}$ at $4^{\circ} \mathrm{C}$, and the protein contents in the supernatant were measured using a Coomassie (Bradford) Protein Assay Kit (Thermo Scientific, Waltham, MA). The protein lysates were denatured at $96^{\circ} \mathrm{C}$ for 10 min after being mixed with SDS loading buffer, and then applied to an SDS polyacrylamide gel for electrophoresis and transferred to nitrocellulose membrane (Amersham Biosciences, Buckinghamshire, UK) [23]. Afterward, the membrane was blocked with $5 \%$ skimmed milk in TBST (150 mM NaCl, $50 \mathrm{mM}$ Tris, pH 7.5, 0.1\% Tween-20). Western blot analysis was performed using specific monoclonal or polyclonal antibodies: cleaved anti-caspase-3, anti-Mcl-1, anti-CHOP, anti-LC3AB, anti-JNK, anti-phospho-JNK (p-JNK), anti-ERK1/2, anti-phospho-ERK1/2 (p-ERK), anti-p38, anti-phospho-p38 (p-p38), anti-AKT (pan), antiphospho-AKT ${ }^{\text {Thr308 }}$ (p-AKT ${ }^{\text {Thr308) }}$ ), and anti-phospho-AKT ${ }^{\text {Ser473 }}$ (p-AKT ${ }^{\text {Ser473 }}$ ) (Cell Signaling Technology, Inc., Beverly, MA); and anti-Bax, anti-Bid, anti-Noxa, anti-Bcl-2, anti-Bcl-xL, anti-GRP78, anti-Gpx-1, anti-SOD-2, anti-HO-1, and anti- $\beta$-actin (Santa Cruz Biotechnology, Inc., Santa Cruz, CA). Blots were then probed with either secondary horseradish peroxide (HRP)-conjugated anti-rabbit or anti-mouse IgG antibodies (Cell Signaling Technology, Inc.). For the detection of proteins, the chemiluminescence agents ECL and ECL Plus were used according to the manufacturer's instructions (Amersham Biosciences) and band signals were visualized using a luminescent image analyzer (LAS4000mini, Fujifilm Co., Tokyo, Japan). Densitometric analysis of protein expression was performed using Image Studio Digits ver. 5.0 (LI-COR Biosciences, Lincoln, NE), and the values were normalized to those of $\beta$-actin.

\section{Statistical analysis}

All experiments are representative of at least three independent replicates. Data are expressed as the mean \pm standard error of the mean. All statistical analyses were performed using GraphPad Prism 5.0 
(Graphpad Prism Software, San Diego, CA). One-way analysis of variance (ANOVA) and two-way ANOVA for group experiments were used for analysis of variance followed by Bonferroni test for multiple comparisons. All $p$-values $<0.05$ were considered statistically significant.

\section{Results}

Reduction in cell viability and enhancement of apoptosis with combined treatment

The cytotoxic effects of BCN were observed from the morphological changes observed under a fluorescence microscope after the cells were stained with Hoechst stain 33258. BCN administered at $100 \mu \mathrm{M}$ alone for $6 \mathrm{~h}$ resulted in a low amount of apoptosis, whereas $50 \mu \mathrm{M}$ was found to be safe (Fig. 1A). Hence, we chose the latter concentration as the maximum for further experimentation. Cell viability was measured to assess the cytotoxic effects of BCN and HT alone and in combination at two different time periods. We found significantly reduced viability after $6 \mathrm{~h}$ and $24 \mathrm{~h}$ in the combination therapy group compared with the non-treated (NT) and HT alone groups (Fig. 1B). Combination therapy dosedependently induced a significant modulation in morphology and increased apoptosis compared with HT alone after $6 \mathrm{~h}$ of postHT incubation (Fig. 1C \& D). DNA fragmentation is a hallmark of apoptosis [24], and therefore DNA fragmentation assay was used to assess the apoptotic effects. HT alone was unable to induce notable levels of apoptosis, whereas its combination with BCN increased the rate of apoptosis in a dose-dependent manner (Fig. 1E). Consistently, the degree of apoptosis was significantly greater in combination treatment than in

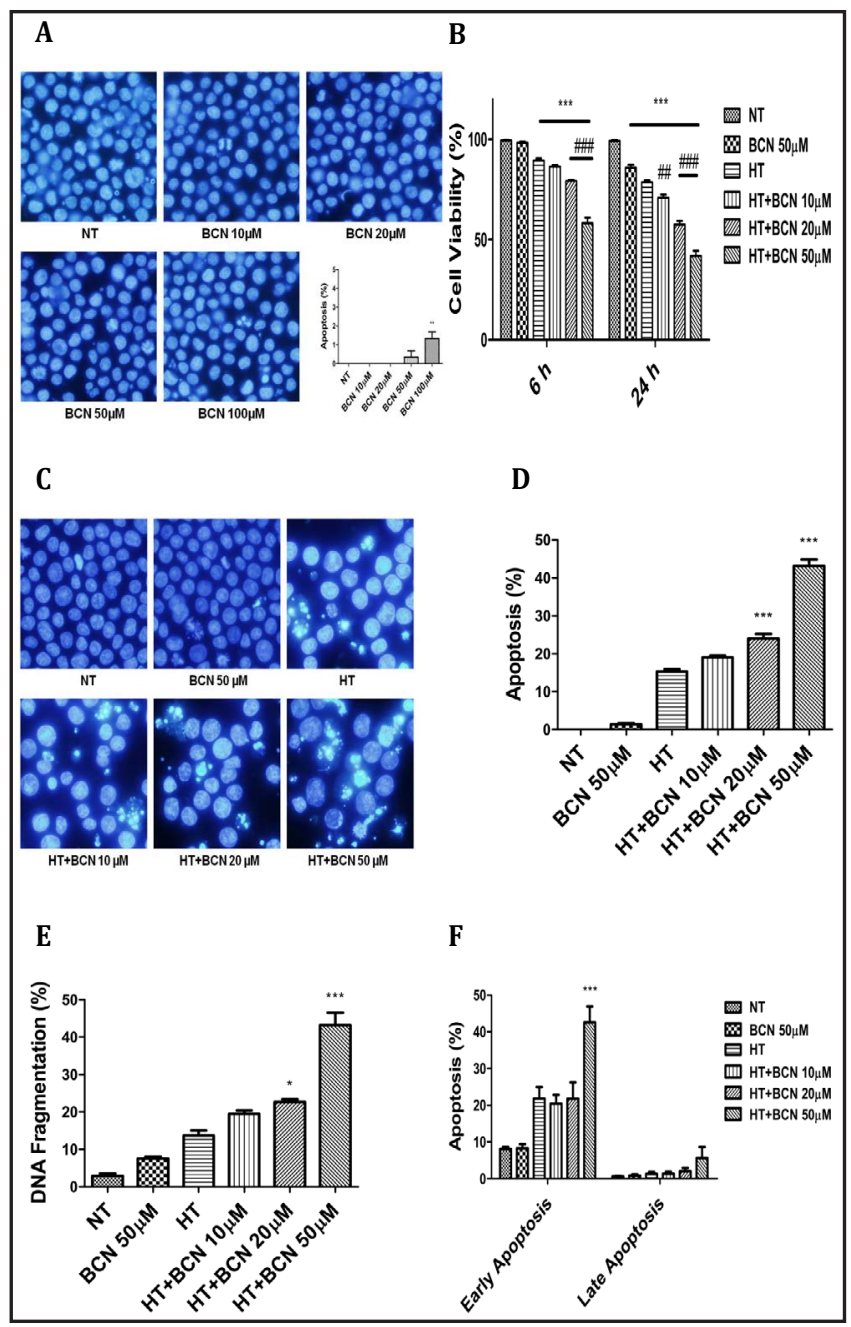

Fig. 1. Baicalin in combination with hyperthermia markedly enhanced apoptosis and reduced the viability of U937 cells. A: U937 cells were treated with BCN (10-100 $\mu \mathrm{M})$ and incubated for $6 \mathrm{~h}$. The morphological changes related to cytotoxicity were visualized by fluorescence microscopy at $400 \times$ magnification after Hoechst staining, and apoptotic cells were counted as the proportion of the total population $(n=300)$. ${ }^{* *} p<0.01$ vs the non-treated (NT) group. B: Cells were treated with hyperthermia (HT) with or without BCN and incubated for $6 \mathrm{~h}$ and $24 \mathrm{~h}$, and cell viability was measured by the Trypan blue exclusion assay. ${ }^{* * *} \mathrm{p}<0.001$ vs the NT group and ${ }^{\# \#} \mathrm{p}<0.01,{ }^{\# \#} \mathrm{p}<0.001$ vs the HT group. U937 cells were treated with HT with or without BCN and incubated for $6 \mathrm{~h}$. C: Morphological changes, such as condensed or fragmented nuclei, reflecting apoptosis, were visualized under a fluorescence microscope at 400× magnification after Hoechst staining. D: Apoptotic cells were counted as the proportion of the total population $(n=300) .{ }^{* * *} \mathrm{p}<0.001$ vs the HT group. E: DNA fragmentation rates were detected by a DNA fragmentation assay. ${ }^{*} \mathrm{p}<0.05$ and ${ }^{* * *} \mathrm{p}<0.001$ vs the HT group. F: Early and late apoptosis rates were analyzed with Annexin V and PI staining by flow cytometry. ${ }^{* * *} \mathrm{p}<0.001$ vs the HT group. 
Fig. 2. Combined treatment of baicalin and hyperthermia upregulated proapoptotic and downregulated antiapoptotic members of the Bcl-2 family and activated the caspase cascade. U937 cells were treated with HT with or without BCN and incubated for 6 h. A \& C: The expression levels of proapoptotic proteins, cleaved caspase-3, and antiapoptotic proteins of the Bcl-2 family were monitored by western blot. B \& D: The relative expression levels of proteins were measured using densitometric analysis by Image Studio Digits ver. 5.0. E: Ratio of Bax/Bcl-2 proteins. $\beta$-actin was used as an internal loading control. ${ }^{* * *} \mathrm{p}<0.001$ vs the NT group and ${ }^{\# \#} \mathrm{p}<0.001$ vs the HT group in Fig. B; ${ }^{* * *} \mathrm{p}<0.001$ vs the HT group in Fig. D \& E.

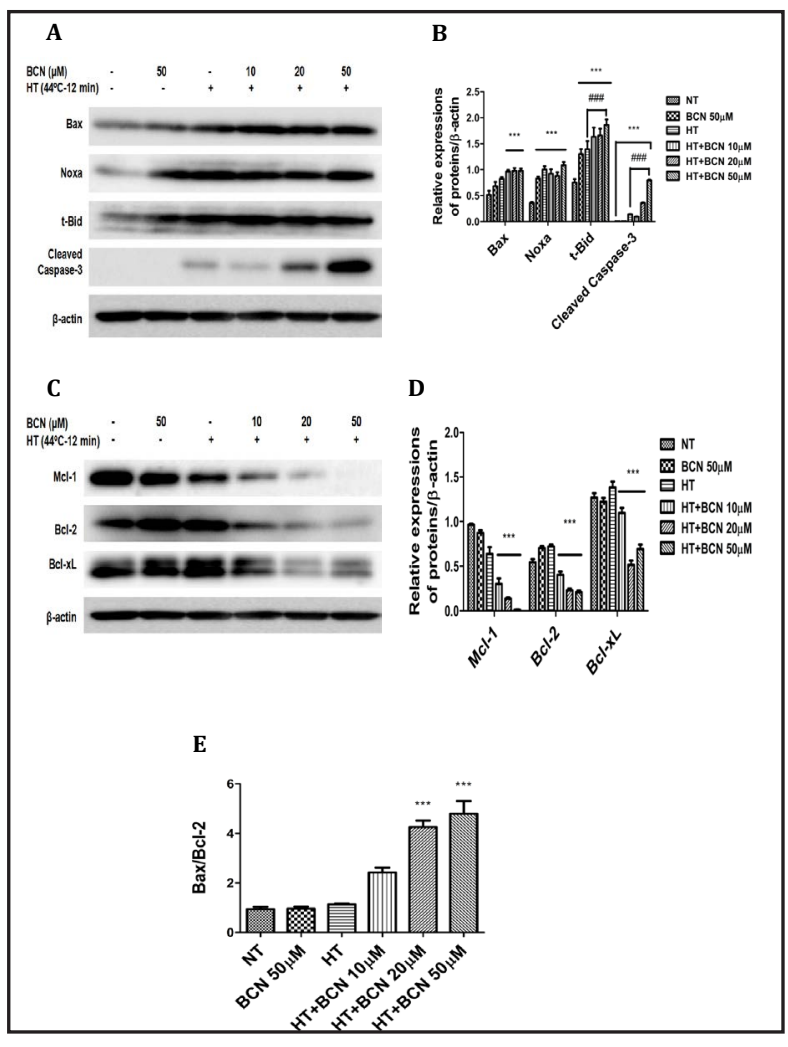

Fig. 3. Loss of mitochondrial transmembrane potential and elevation of mitochondrial free calcium with baicalin combined with hyperthermia. Mitochondrial membrane potential was measured by flow cytometry after the cells were treated with HT with or without BCN and incubated for $3 \mathrm{~h}$. A: Overlay histogram representing mitochondrial membrane potential loss with the formation of left-side waves indicates loss of potential, compared with the right side wave showing high potential in control and healthy cells. Y-axis shows the number of cells. X-axis shows the potential of the mitochondrial membrane. B: Fraction of cells with a low mitochondrial transmembrane potential (MMP) (\%). ${ }^{* * *} \mathrm{p}<0.001$ vs the NT group and ${ }^{\#} \mathrm{p}<0.05$ vs the HT group. C: Mitochondrial calcium was detected by the cell-permeable calcium indicator Rhod 2-AM. Cells were pre-

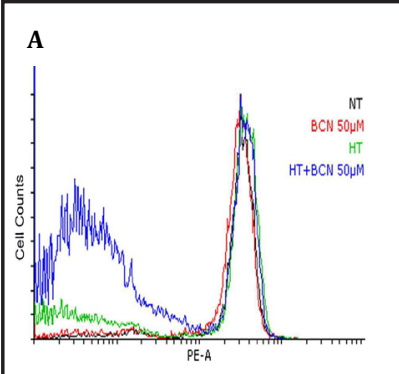

C

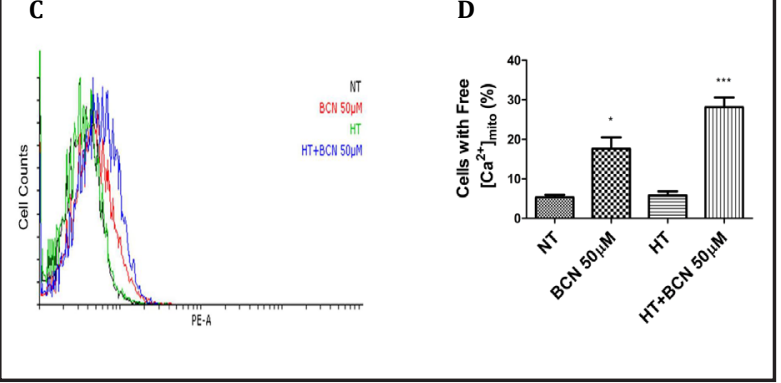
loaded with the stain before being treated with

HT with or without BCN for $3 \mathrm{~h}$ and were analyzed by flow cytometry. Overlay histogram representing high mitochondrial free calcium with a shift of waves toward the right, as compared with the control wave with low fluorescent intensity. Y-axis shows the number of cells. X-axis shows the fluorescent intensity of the cells with mitochondrial free calcium. D: Fraction of cells with mitochondrial free calcium (\%). ${ }^{*} \mathrm{p}<0.05$ and ${ }^{* * *} \mathrm{p}<0.001$ vs the NT group.

individual treatment, as detected by flow cytometry with FITC-induced Annexin V and PI staining (Fig. 1F). 


\section{Cellular Physiology Cell Physiol Biochem 2018;45:2444-2460 \begin{tabular}{c|c|c|} 
DOI: 10.1159/000488263 & and Biochemistry & $\begin{array}{l}\text { O } 2018 \text { The Author(s). Published by S. Karger AG, Basel } \\
\text { wwww.karger.com/cpb }\end{array}$
\end{tabular}

Upregulation of proapoptotic proteins and caspase activation

Proapoptotic proteins such as Bax, Noxa, and Bid are Bcl-2 family proteins that are critical to the induction of apoptosis via the intrinsic pathway, which leads to activation of the caspase cascade, with consequent cleavage of the effector caspase caspase- 3 . In this study, expressions of proapoptotic proteins were visualized by western blot analysis, and Bax and Noxa were markedly higher in combination therapy cells than in NT cells, although there was little change from HT-treated cells. Bid is a BH3-only protein that is also cleaved into an active form, called truncated Bid, which interacts with Bax and results in efficient permeabilization of the mitochondrial membrane. Our results showed that caspase- 3 was also significantly and dose-dependently activated in combination treatment cells compared with HT-treated cells (Fig. 2A \& B).

\section{Downregulation of antiapoptotic proteins}

Anti-apoptotic proteins such as Bcl-2, Bcl-xL, and Mcl-1 are also Bcl-2 family proteins. In contrast to proapoptotic proteins, these survival proteins increase growth by binding to BH3only proteins to inhibit their interaction with and activation of Bax or Bak, thereby inhibiting apoptosis induction. In this study, expressions of antiapoptotic proteins were visualized by western blotting, and it was seen that these proteins were drastically downregulated with combination treatment compared with the HT group, indicating the downregulation of survival factors and resulting in apoptosis induction (Fig. 2C \& D). The ratio of Bax to Bcl-2 was highly increased in the combination group compared with the HT group (Fig. 2E).

\section{Loss of mitochondrial membrane potential}

MMP plays a vital role in intracellular signal transduction, and its dysfunction leads to apoptosis [17]. Although HT and BCN both affect MMP [19, 25], the effects of combined therapy needed to be explored. Therefore, we analyzed the change in the MMP with both individual and combined treatments, finding that there was a significant loss in MMP in the combination treatment group compared with the NT and HT groups (Fig. 3A \& B).

\section{Elevation of mitochondrial free calcium}

Calcium signaling is crucial to cell fate by influencing mitochondrial-interconnected processes, such as energy production and apoptosis [26]. Both HT and BCN alone can increase free intracellular calcium $[19,25]$. However, the effect of combined treatment was unknown. Therefore, we detected the mitochondrial free calcium using Rhod 2-AM, finding that HT and BCN in combination significantly increased the mitochondrial free calcium compared with the NT and HT groups. BCN alone also increased the calcium level compared with the NT group (Fig. 3C \& D).

Increase in oxidative stress and suppression of the antioxidant system

Oxidative stress contributes to apoptotic signaling initiation via the production of ROS [27]. HT and BCN individually generate ROS $[28,29]$. Therefore, we used flow cytometry to assess the level of ROS with combined treatment and found that combined treatment also significantly increased the levels of superoxide radicals (Fig. 4A \& B) and hydrogen peroxide (Fig. 4C \& D) after 30 min of incubation compared with the individual treatment groups. Furthermore, to confirm the involvement of the antioxidant system, we analyzed the expression levels of proteins involved in the antioxidant system, including Gpx-1, SOD-2, and $\mathrm{HO}-1$, and found them to be suppressed after the induction of oxidative stress (Fig. 4E \& F). These results also indicated that ROS actively participates in apoptosis enhancement by suppressing the antioxidant system.

\section{Modulations of MAPK and AKT pathways}

The MAPK pathway is involved in the regulation of cell cycle progression, cell survival, and death responses after exposure to a variety of stimuli [30]. Therefore, we analyzed the activated or phosphorylated forms of the members of the subfamilies of the MAPK path- 
way, including JNK, $\mathrm{ERK} 1 / 2$, and p38. JNK and p38 were significantly and dose-dependently phosphorylated in the combination therapy cells compared with HT treatment alone, whereas ERK1/2 was dephosphorylated (Fig. 5A \& B). The change in the dephosphorylation of ERK was slight, but the ratio between p-JNK and p-ERK was significantly increased, indicating the fate of cells exposed to the combined treatment (Fig. 5C).

Akt serine/ threonine is a regularly activated kinase that is associated with cell proliferation, cellular energy metabolism, and a n t i a p op tos is $[31,32]$. Akt is an upstream signal to the cell survival and death mechanism as well as deactivation of the Akt, whereas activation of the MAPK pathway also contributes to the enhancement of apoptosis [33, 34]. When BCN was combined with HT,

a significant dephosphorylation of Akt at both $\mathrm{Thr}^{308}$ and Ser ${ }^{473}$ amino acid residues occurred compared with the NT group and the BCN alone cells. However, HT alone also markedly changed the level of Akt phosphorylation (Fig. 5D \& E). Taken together, these findings indicated that increased phosphorylation of JNK and p38 contributed to the enhancement of apoptosis and that dephosphorylation of ERK and Akt was somehow involved. Nonetheless, further studies are needed to elucidate the exact molecular mechanism involved.
Fig. 4. Increased generation of intracellular reactive oxygen species and suppression of antioxidant enzymes with combined treatment of baicalin and hyperthermia. Intracellular reactive oxygen species (ROS) generation was detected in U937 cells after treatment with HT with or without BCN by staining with dihydroethidium for superoxide radicals and DCFH-DA for hydrogen peroxide. After $30 \mathrm{~min}$ of post-treatment incubation, cells were harvested, washed with phosphatebuffered saline,
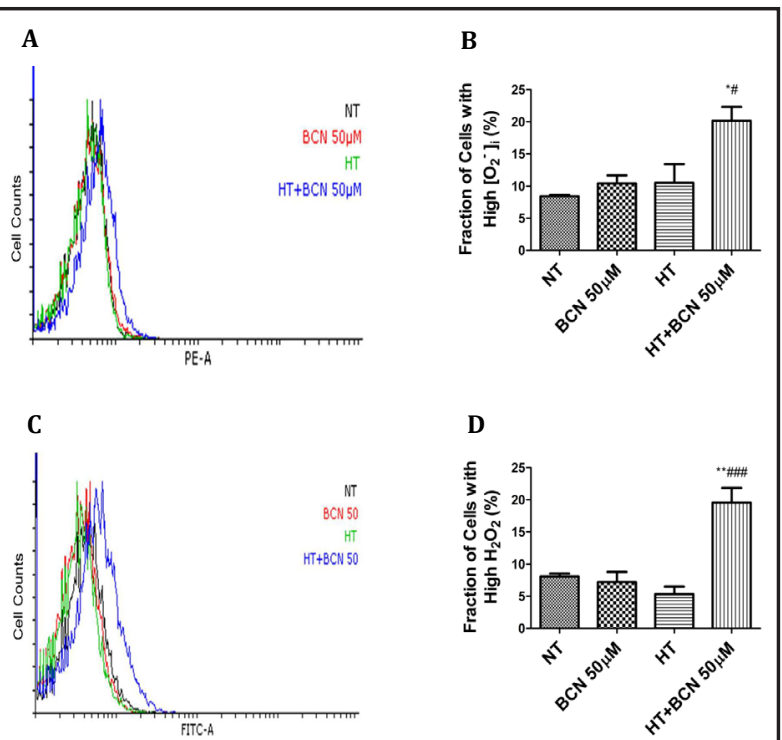

$\mathbf{E}$

$\mathbf{F}$

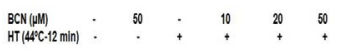

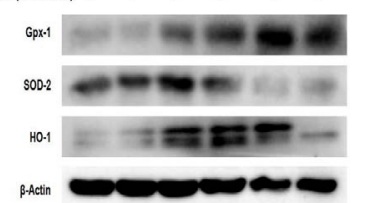
and stained with $4 \mu \mathrm{M}$ of dihydroethidium and $20 \mu \mathrm{M}$ DCFH-DA for $30 \mathrm{~min}$ at $37^{\circ} \mathrm{C}$ in separate samples and analyzed by flow cytometry. A: Overlay histogram representing high intracellular superoxide radicals with a shift of the waves toward the right, as compared with the control wave with low fluorescent intensity. Y-axis shows the number of cells. X-axis shows the fluorescent intensity of the cells with high intracellular superoxide. B: Fraction of cells with high intracellular superoxide (\%). ${ }^{*} \mathrm{p}<0.05$ vs the NT group and ${ }^{~} \mathrm{p}<0.05$ vs the HT group. C: Overlay histogram representing high intracellular hydrogen peroxide generation with a shift of the waves toward the right, as compared with the control wave with low fluorescent intensity. Y-axis shows the number of cells. X-axis shows the fluorescent intensity of the cells with high $\mathrm{H}_{2} \mathrm{O}_{2}$ D: Fraction of cells with high $\mathrm{H}_{2} \mathrm{O}_{2}$

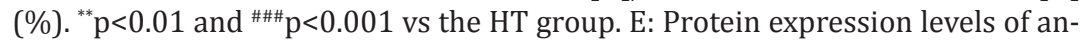
tioxidant enzymes were analyzed by western blotting after the cells were treated with HT, with or without the indicated concentrations of BCN. F: The relative expression levels of proteins were quantified by densitometric analysis. $\beta$-actin was used as an internal loading control. "** $\mathrm{p}<0.001$ vs the NT group and ${ }^{\circledR} \mathrm{p}<0.05$ vs the HT+BCN $20 \mu \mathrm{M}$ group for Gpx-1 and HO-1, and vs the HT group for SOD-2. 
Fig. 5. Western blot analysis of proteins related to signal transduction pathways under the influence of hyperthermia and baicalin treatment. U937 cells were harvested after 30 min of post-treatment with HT and BCN and lysed for protein extraction and western blotting analysis of protein expression. A-C: The expression levels of the phosphorylated and total forms of ERK, JNK, and p38 proteins and their relative expression levels were quantified by densitometric analysis. The ratio of p-JNK/p-ERK was also evaluated to determine the changes in these proteins. $\quad{ }^{* * *} \mathrm{p}<0.001$, ${ }^{* *} \mathrm{p}<0.01,{ }^{*} \mathrm{p}<0.05$ vs the HT group. D \& E: The expression levels of the phosphorylated and total forms of Akt and their relative expression levels were quantified by densitometric analysis. $\quad{ }^{* * *} \mathrm{p}<0.001$, ${ }^{* *} \mathrm{p}<0.01$ vs the NT group. F-H: The expression levels of the ER stress-related markers

GRP78 and CHOP and the autophagic marker LC3AB were analyzed and quantified via densitometric analysis. $\beta$-actin was used as an internal loading control. ${ }^{* *} \mathrm{p}<0.001,{ }^{*} \mathrm{p}<0.05$ vs the HT group for GRP78 and CHOP and ${ }^{* * *} \mathrm{p}<0.001,{ }^{* *} \mathrm{p}<0.01$ vs the NT group for LC3AB.

\section{Upregulation of ER stress and autophagic markers}

The ER stress-mediated pathway also plays a role in the induction of apoptosis [8]. Thus, the protein expression levels of ER stress markers such as GRP78 and the transcription factor CHOP were examined using western blot analysis. The experiments revealed their significant activation in the combined treatment groups compared with the HT group (Fig. 5F \& G), indicating that ER stress was markedly increased by the combined treatment.

Autophagy is a cellular homeostatic mechanism that protects cells from stress or damage [35]. Previously, AKT suppression was found to be involved in autophagy [36], and microtubule-associated protein 1 light chain 3 (LC3) is considered to be a hallmark of autophagy processes [37]. Moreover, BCN also triggers autophagy in T24 cells through the 
Fig. 6. Use of inhibitors reveals the involvement of the MAPK pathway via ROS generation in the enhancement of apoptosis. U937 cells were exposed to the indicated concentrations of JNK-IN-8 (a JNK inhibitor), NAC (a ROS scavenger), BAPTA-AM (a calcium chelator), and Tudca (an ER stress inhibitor) for $30 \mathrm{~min}$ before combined treatment, and western blotting and DNA fragmentation analysis were used to determine their effects. A \& $\mathrm{B}$ : The expression of the phosphorylated form of JNK and its relative expression level was quantified by densitometric analysis. ${ }^{* * *} \mathrm{p}<0.001$ vs the NT group and ${ }^{\#} \mathrm{p}<0.05$ vs the HT group. C \& D: The expression levels of GRP78, LC3AB, and cleaved caspase- 3 and their relative expression levels were quantified by densitometric analysis. $\beta$-actin was used as an internal loading control. ${ }^{* *} \mathrm{p}<0.001$ vs the NT group and ${ }^{\#} \mathrm{p}<0.05$, ${ }^{\# \#} \mathrm{p}<0.01$, $\# \#$ p $<0.001$ vs the HT group. ns, non-significant. E-H: The rate of DNA fragmentation with combined treatment with or without use of inhibitors. ${ }^{* * *} \mathrm{p}<0.001$ vs the NT group and ${ }^{\# \#} \mathrm{p}<0.01,{ }^{\# \# \#} \mathrm{p}<0.001$ vs the HT group. ns, non-significant.

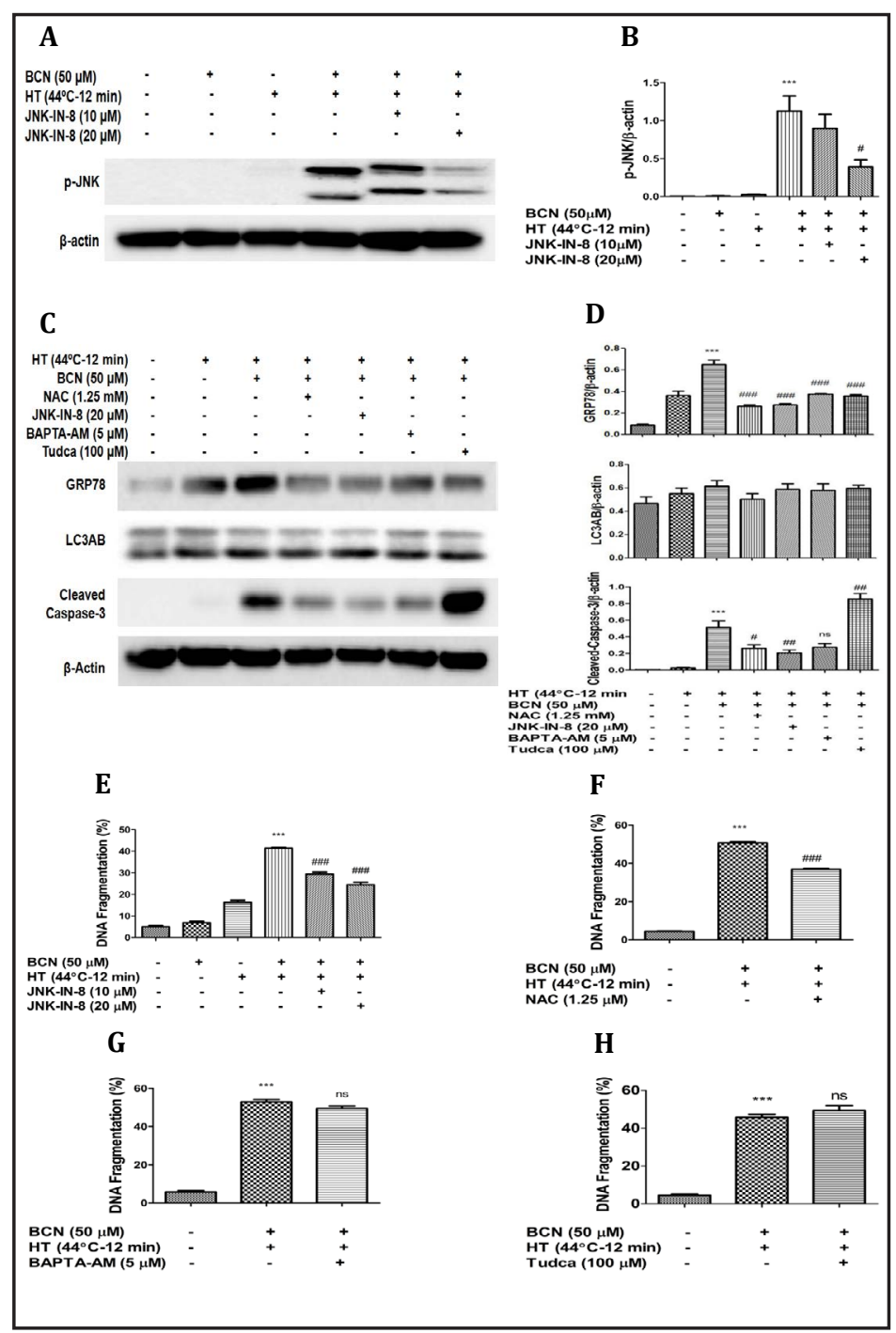

Akt pathway [31]. Hence, we assessed the protein levels of LC3AB by western blot, finding significant changes in the expression of LC3AB when cells were treated with the combined therapy, indicating that some autophagic processes were involved (Fig. 5F \& H).

\section{JNK inhibitor and NAC potentially abrogated the effects of combined treatment}

JNK phosphorylation was actively involved in the mechanism underlying apoptosis induction. Thus, we used $10 \mu \mathrm{M}$ and $20 \mu \mathrm{M}$ of JNK-IN-8 (JNK inhibitor) $30 \mathrm{~min}$ before combined treatment of HT and BCN, finding suppressed expression of p-JNK (Fig. 6A \& B) and cleaved caspase-3 (Fig. 6C \& D) in western blotting and a recovered rate of apoptosis in the DNA fragmentation assay (Fig. 6E). These findings show that the JNK pathway was actively involved in the underlying mechanism.

In addition, we used other inhibitors, including NAC (a ROS scavenger), BAPTA-AM (a calcium chelator), and Tudca (an ER stress inhibitor), because the levels of ROS, $\mathrm{Ca}^{2+}$, and ER stress were also increased in our study. NAC significantly alleviated the apoptotic effects of the combination treatment, as evidenced by suppressed western blot expression of cleaved caspase-3 (Fig. 6C \& D), and rescued the apoptosis revealed by DNA fragmentation (Fig. 6F). On the other hand, BAPTA-AM slightly but not significantly suppressed the expression of cleaved caspase-3 (Fig. 6C \& D) and had a minor effect in the DNA fragmentation assay (Fig. $6 \mathrm{G}$ ), indicating that $\mathrm{Ca}^{2+}$ does not contribute notably to the enhancement of apoptosis. Tudca 


\section{Cellular Physiology Cell Physiol Biochem 2018;45:2444-2460

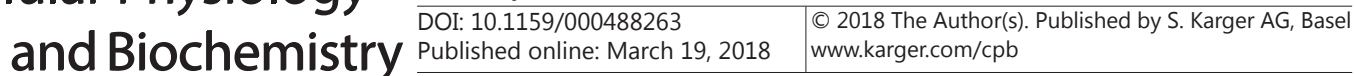 \\ Zakki et al.: Baicalin Augments Hyperthermia-Induced Apoptosis}

inhibited the protein expression of GRP78 induced by combination treatment, but there was a significant increase in the expression of cleaved caspase-3 (Fig. 6C \& D) and the rate of apoptosis by DNA fragmentation was unaltered (Fig. 6H). In addition, in the presence of all of these upstream inhibitors, GRP78 was significantly suppressed in the combined treatment group, whereas the alterations in the expression of LC3AB were insignificant (Fig. 6C \& D). These results indicate that autophagy was not the downstream pathway or the contributing factor leading to cell death in the present study. However, the exact mechanism is still obscure and needs further work. To conclude, ROS generation helped in the enhancement of apoptosis induced by HT and BCN treatment, and MAPK was the signaling pathway involved.

\section{Discussion}

HT is reported to be a good strategy for cancer both by itself [1] and in conjunction with radiotherapy or chemotherapy [38,39]. In addition, it is now considered a potential tool for treating cancer after surgery, radiotherapy, and chemotherapy. However, normal cells are also damaged by HT [3]. To overcome this limitation, we used a short exposure time for HT and combined it with an enhancer for better results.

Purified BCN has antiproliferative and apoptotic effects in prostate cancer cell lines [40], human ovarian cancer cell lines [41], human T24 bladder cancer cells [31], HeLa cervical cancer cells [11], breast cancer cells [6], hepatic cancer cells [8, 9], the A549 lung cancer cell line [42], CA46 Burkitt lymphoma cells [24], HL-60 promyelocytic leukemia cells [25], and human leukemia cell lines $[15,16]$. BCN is also reported to be more potent than baicalein (due to the lack of a glucuronate group) in human hepatoma cells [43]. These studies reported that BCN alone could induce apoptosis in the U937 cell line. However, the apoptotic effects were concentration- and time-dependent and a high concentration was required to achieve a sufficient rate of apoptosis, with one study reporting an $\mathrm{IC}_{50}$ value for BCN of $50 \mu \mathrm{g} / \mathrm{mL}$ after $96 \mathrm{~h}$ of treatment [15] and another reporting that $15 \mu \mathrm{g} / \mathrm{mL}$ of BCN inhibited the growth of U937 cells by $50 \%$ after $72 \mathrm{~h}$ [16]. In the present study, the combination of BCN and HT significantly reduced cell viability, increased DNA fragmentation, and elevated cell death determined by morphological apoptotic body formation and Annexin V/PI-stained cells.

The intrinsic pathway of apoptotic cell death mainly involves Bcl-2 family proteins comprising proapoptotic members such as Bax, Noxa, and Bid and antiapoptotic members such as Bcl-2, Bcl-xL, and Mcl-1. In the presence of any death stimuli, Bid transforms into the activated or truncated form t-Bid and activates Bax, which consequently induces pore formation in the mitochondrial outer membrane. In addition, Noxa binds to Mcl-1, whereas the BH3-only protein Bad interacts with $\mathrm{Bcl}-2$ and deactivates it, resulting in an increased $\mathrm{Bax} / \mathrm{Bcl}-2$ ratio that indicates activation of the caspase cascade [44]. In the present study, proapoptotic proteins were highly expressed, whereas antiapoptotic proteins were suppressed when BCN was combined with HT compared with the HT group, indicating the active role of $\mathrm{Bcl}-2$ family proteins in the apoptosis. Caspase proteinases control apoptotic signaling and execution by cleaving cellular proteins after aspartate residues. Initiator caspases are cleaved and activated by death stimuli and then activate executioner caspases and promote apoptosis by cleaving cellular substrates that induce the morphologic and biochemical alterations inherent to apoptosis [45]. In our study, combined treatment activated the cleaved form of caspase-3. Collectively, the alterations in the Bcl-2 family proteins and activation of the caspase cascade indicated the involvement of the intrinsic pathway in the enhancement of apoptosis.

Ample mitochondrial functions are indispensable to many processes, including apoptosis and metabolic signaling pathways, and MMP loss is linked to triggering of cell death by caspase activation [7]. In the present study, MMP was significantly decreased with combined treatment, confirming the involvement of the mitochondrial/intrinsic pathway of cell death. It was previously reported that BCN induced apoptosis in human promyelocytic leukemia HL-60 cells [25], in lymphocytic leukemia, lymphoma, and myeloma cell lines [15], 


\section{Cellular Physiology Cell Physiol Biochem 2018;45:2444-2460

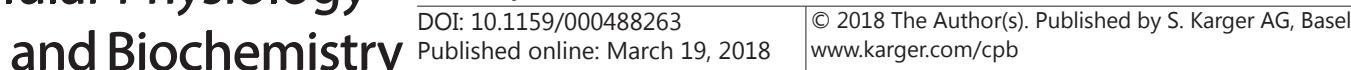

Zakki et al.: Baicalin Augments Hyperthermia-Induced Apoptosis

and in a human leukemia cell line [16] by decreasing their MMP. The present study is the first study to report the loss of MMP with combined treatment of BCN and HT. On the other hand, a review study highlighted the mitochondrial protective effects of BCN and baicalein in different types of cell lines [7]. Taken together, BCN possesses two types of effects, depending on the nature of the cell line being used and the type of administration.

ROS are the byproducts of molecular oxygen generated as a result of metabolism in living systems and play a vital role in cell signaling and homeostasis. Superoxide is the precursor of ROS and is crucial to the oxidative chain reaction. Hydrogen peroxide is produced when superoxide is dismutated by the enzyme superoxide dismutase [46]. Here, both superoxide and hydrogen peroxide were elevated soon after combined treatment, which thereafter activated the antioxidant system. The antioxidant enzymes SOD, Gpx-1, and HO-1 were increased in the early stages (data not shown), with suppression later on due to the chronic toxicity of oxidative stress. These results indicated that the antioxidant system was activated to protect the cells at the beginning of the treatment but that combined treatment had potential cytotoxic effects that suppressed the antioxidant enzymes and eventually led to the death of the cells. In agreement with the present findings, a few studies have reported ROS as a precursor of apoptosis [10,25]. However, in others, ROS was scavenged by BCN and alleviated apoptosis [29, 47]. HT induces apoptosis by increasing oxidative radicals [19]. Therefore, we can speculate that the pro-oxidant behavior of BCN in our findings might be due to the influence of HT. The role of ROS in the enhancement of apoptosis was evident with the use of NAC, which not only suppressed the expression of caspase-3, but also protected the cells, as revealed by DNA fragmentation.

MAPKs are involved in transmitting extracellular stimuli to the nucleus through various signal transduction pathways. The MAPK pathway comprises intracellular kinases important to cancer development [48] and apoptosis control [49]. JNK is responsible for apoptosis induction, whereas ERK protects against it and promotes proliferation [3]. Accordant results were found in the present study, with JNK and p38 significantly phosphorylated in combination therapy and ERK dephosphorylated. These results indicated that the MAPK pathway was potentially involved in transducing the signals from extracellular stimuli to the nucleus for transcriptional changes and consequent induction of apoptosis. JNK and p38MAPK are well-known stress-activated protein kinases that evoke sequential interactions related to cell death or survival [50]. In particular, p38 is also a marker of oxidative stress, which increases the phosphorylation levels of p38 [44, 51], consistent with our findings and supporting the claim that oxidative stress is involved in the mechanism underlying the combined treatment. In addition, the balance between the activation of the stress-related kinase JNK and suppression of the growth-related kinase ERK is the determinant of cell fate between apoptosis and cell survival $[32,50]$, which is in agreement with our findings. Ostensibly, the change in the expression of p-ERK was not significant, but the ratio of p-JNK to $\mathrm{p}$-ERK was significantly involved in the pathway exploited by the underlying mechanism. Moreover, the involvement of JNK was evident with the use of a JNK inhibitor, which blocked the activation of JNK with combined treatment, suppressed the activation of caspase-3, and rescued the cells, as detected by DNA fragmentation.

The PI3K/Akt growth signaling pathway comprises a family of phosphorylationregulated intracellular protein kinases. The primary activator of this signaling pathway is activated/phosphorylated Akt, which potentiates the survival of various tumors by activating downstream targets [24]. Its phosphorylation at $\mathrm{Thr}^{308}$ increases its activity while its phosphorylation at Ser ${ }^{473}$ is required for its full activation, which eventually suppresses various proapoptotic signaling molecules involved in cell growth and proliferation [52]. Activation of JNK usually occurs from the activation of ASK1, which is a target of Akt inhibitory phosphorylation, and provides the direct link between Akt and JNK $[34,53$, 54]. Sometimes induction of apoptosis is done by following the pathway of RAF1-ERK or ASK1-JNK signals, especially in the presence of any kind of stress [30]. However, some reports also reflect that Akt signals exist side by side with the MAPK pathway and play a role in the induction of apoptosis $[55,56]$. Akt may also be involved when there is some 
Fig. 7. Schematic illustration showing the combined effect of baicalin and hyperthermia in the enhancement of apoptosis. BCN in combination with HT increased ROS generation, suppressed the anti-oxidant enzymes in U937 cells, and activated the MAPK pathway with inhibition of the Akt signals. Alterations in Bcl-2 family proteins were also observed accompanied with increases in mitochondrial calcium, ER stress, and autophagy, which led to mitochondrial dysfunction and ultimately activation

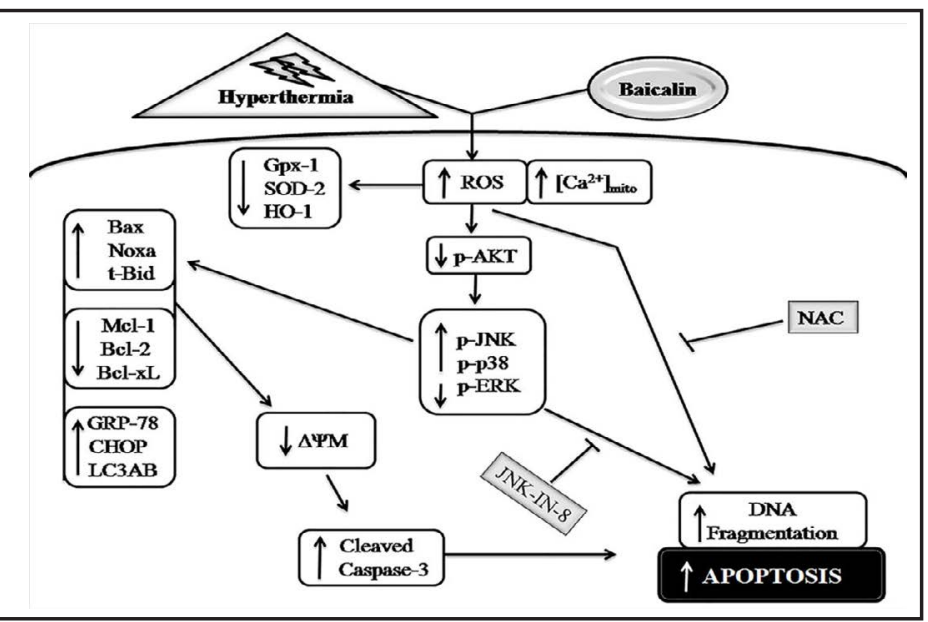
of the caspase cascade. Finally, enhancement of apoptosis leading to cell death was found with the combined treatment, which could be rescued by JNK inhibitor and NAC.

autophagy regulation [31,33]. The anti-apoptotic Mcl-1 gene is activated and upregulated by the PI3/Akt signaling pathway, and suppression of Mcl-1 by inhibition of Akt is required for cell shrinkage-dependent apoptosis [57]. Likewise, the present study observed the aforementioned signals, indicating deactivation of Akt and Mcl-1 and activation of JNK are closely correlated with the induction of apoptosis, as reported previously [34]. The increase in ER stress, which is consistent with another finding of apoptosis with the same signaling pathway [55]. Moreover, in the present study, activation of the autophagic marker LC3AB and suppression of Akt phosphorylation were observed with combined treatment as well as with HT alone, although the difference between them was not significant. These findings may indicate the involvement of this pathway in the underlying mechanism, although not a remarkable contribution. Akt is an early participant in the pathway, but the exact involvement of PI3K in the BCN and HT combination treatment still remains obscure. Growth suppressive effects and autophagy may contribute to the interaction of the indicated treatment with these kinases, and further work is required to identify the exact mechanisms involved.

$\mathrm{Ca}^{2+}$ is an important regulator of human cell metabolism, differentiation, life, and death by interacting with various signaling pathways, and its level needs to be controlled to maintain homeostasis [58]. BCN enhances the intracellular $\mathrm{Ca}^{2+}$ in human HL-60 promyelocytic leukemia cells [25] and human MDA-MB-231 breast cancer cells [59]. In agreement with previous findings, intracellular $\mathrm{Ca}^{2+}$ was increased by BCN treatment alone in U937 cells, but not by combined treatment (data not shown). However, mitochondrial $\mathrm{Ca}^{2+}$ was significantly increased in the combined treatment group. Consistently, mitochondrial $\mathrm{Ca}^{2+}$ was also markedly increased with BCN alone. Although the level of mitochondrial $\mathrm{Ca}^{2+}$ was increased, BAPTA-AM insignificantly abrogated the caspase-3 activation and DNA fragmentation, revealing that it was not the component responsible for the enhancement of apoptosis. Nonetheless, further studies are needed.

The ER is a substantial intracellular organ for protein folding and modification and calcium storage that plays a pivotal role in signal transduction. Accumulation of misfolded proteins or aberrant folding capacity may lead to what is known as ER stress [30], which is evident by high expression of the ER stress molecular marker GRP78 [8] and the C/EBP homologous transcription factor CHOP [25]. Here, both GRP78 and CHOP were markedly higher with combination therapy than with HT alone. GRP78 was also suppressed by various upstream signal inhibitors such as NAC, JNK-IN-8, BAPTA-AM, and Tudca. However, Tudca could not suppress the activation of caspase- 3 with combined treatment, but showed a slight increase, consistent with the DNA fragmentation results. This indicates that it could not rescue cells from apoptosis. Collectively, combined treatment increased ER stress in the 


\section{Cellular Physiology Cell Physiol Biochem 2018;45:2444-2460

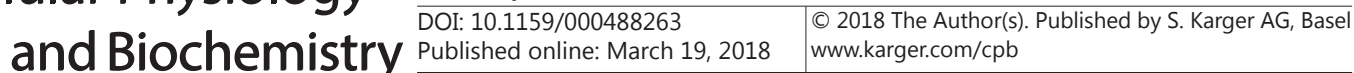 \\ Zakki et al.: Baicalin Augments Hyperthermia-Induced Apoptosis}

cell system. However, it was not the contributing factor leading to cell death, as reported previously in the case of BCN alone [8,25], but further studies are nonetheless required.

Taken together, our schematic illustration (Fig. 7) shows that BCN plays a prominent role, particularly when combined with HT, in enhancing cell death in U937 cells. The combined treatment increased the ROS generation with ultimate suppression of the antioxidant enzymes, which subsequently led to the loss of MMP and increases in ER stress and mitochondrial calcium. Consequently, the increase in Bax/Bcl-2 and decrease in Mcl-1 caused release of cytochrome $\mathrm{c}$ and further activation of the mitochondrial-dependent apoptotic pathway, as revealed by fragmentation of the DNA, induction of apoptosis, formation of apoptotic bodies, reduction in cell viability, and activation of caspase-3, leading to cell death. The MAPK pathway was shown to be the underlying mechanism of signal transduction in this study, but the interaction of MAPK and Akt remains unclear and needs further study.

\section{Conclusion}

In conclusion, BCN markedly augmented HT-induced apoptosis in U937 cells with the involvement of the MAPK pathway via elevation of intracellular ROS and activation of the mitochondrial/intrinsic apoptotic pathway. The limitations of the HT strategy may be overcome through the use of an augmentor such as BCN. This should pave the way to boosting the efficacy of the HT therapy and represents a novel finding in the field of cancer therapeutics.

\section{Acknowledgements}

This research did not receive any specific grant from funding agencies in the public, commercial, or non-profit sectors.

\section{Disclosure Statement}

The authors declare no Disclosure Statement.

\section{References}

1 Ahmed K, Tabuchi Y, Kondo T: Hyperthermia: an effective strategy to induce apoptosis in cancer cells. Apoptosis 2015;20:1411-1419.

- Cui Z-G, Piao J-L, Kondo T, Ogawa R, Tsuneyama K, Zhao Q-L, Feril LB, Inadera H: Molecular mechanisms of hyperthermia-induced apoptosis enhanced by docosahexaenoic acid: implication for cancer therapy. Chem Biol Interact 2014;215:46-53.

3 Cui Z-G, Piao J-L, Rehman MUR, Ogawa R, Li P, Zhao Q-L, Kondo T, Inadera H: Molecular mechanisms of hyperthermia-induced apoptosis enhanced by withaferin A. Eur J Pharmacol 2014;723:99-107.

-4 Abbasi P, Shamsasenjan K, Movassaghpour Akbari AA, Akbarzadehlaleh P, Dehdilani N, Ejtehadifar M: The effect of baicalin as a PPAR activator on erythroid differentiation of CD133 (+) hematopoietic stem cells in umbilical cord blood. Cell J 2015;17:15-26.

5 Ma H, He X, Yang Y, Li M, Hao D, Jia Z: The genus Epimedium: An ethnopharmacological and phytochemical review. J Ethnopharmacol 2011;134:519-541.

6 Lee D, Ko W, Hwang D, Heo DN, Lee SJ, Heo M, Lee K, Ahn J, Jo J, Kwon I: Use of baicalin-conjugated gold nanoparticles for apoptotic induction of breast cancer cells. Nanoscale Res Lett 2016;11:381.

7 de Oliveira MR, Nabavi SF, Habtemariam S, Erdogan Orhan I, Daglia M, Nabavi SM: The effects of baicalein and baicalin on mitochondrial function and dynamics: A review. Pharmacol Res 2015;100:296-308. 


\section{Cellular Physiology Cell Physiol Biochem 2018;45:2444-2460 \begin{tabular}{l|l|l|}
\hline DOI: 10.1159/000488263 & 2018 The Author(s). Published by S. Karger AG, Basel \\
\hline
\end{tabular} and Biochemistry

8 Yu Z, Luo X, Wang C, Ye J, Liu S, Xie L, Wang F, Bao J: Baicalin promoted site-2 protease and not site-1 protease in endoplasmic reticulum stress-induced apoptosis of human hepatocellular carcinoma cells. FEBS Open Bio 2016;6:1093-1101.

-9 Yu Y, Pei M, Li L: Baicalin induces apoptosis in hepatic cancer cells in vitro and suppresses tumor growth in vivo. Int J Clin Exp Med 2015;8:8958-8967.

10 Ueda S, Nakamura H, Masutani H, Sasada T, Takabayashi A, Yamaoka Y, Yodoi J: Baicalin induces apoptosis via mitochondrial pathway as prooxidant. Mol Immunol 2002;38:781-791.

11 Peng Y, Fu ZZ, Guo CS, Zhang YX, Di Y, Jiang B, Li QW: Effects and mechanism of baicalin on apoptosis of cervical cancer hela cells in-vitro. Iran J Pharm Res 2015;14:251-261.

12 Goldar S, Khaniani MS, Derakhshan SM, Baradaran B: Molecular mechanisms of apoptosis and roles in cancer development and treatment. Asian Pacific J Cancer Prev 2015;16:2129-2144.

13 Signore M, Ricci-Vitiani L, De Maria R: Targeting apoptosis pathways in cancer stem cells. Cancer Lett 2013;332:374-382.

-14 Ciesielska E, Wolszczak M, Gulanowski B, Szulawska A, Kochman A, Metodiewa D: In vitro antileukemic, antioxidant and prooxidant activities of Antoksyd S (C/E/XXI): a comparison with baicalin and baicalein. In vivo 2004;18:497-503.

15 Kumagai T, Müller CI, Desmond JC, Imai Y, Heber D, Koeffler HP: Scutellaria baicalensis, a herbal medicine: Anti-proliferative and apoptotic activity against acute lymphocytic leukemia, lymphoma and myeloma cell lines. Leuk Res 2007;31:523-530.

16 Shieh D-E, Cheng H-Y, Yen M-H, Chiang L-C, Lin C-C: Baicalin-induced apoptosis is mediated by Bcl-2dependent, but not p53-dependent pathway in human leukemia cell lines. Am J Chin Med 2006;34:245261.

17 Cui ZG, Ogawa R, Piao JL, Hamazaki K, Feril LB, Shimomura A, Kondo T, Inadera H: Molecular mechanisms involved in the adaptive response to cadmium-induced apoptosis in human myelomonocytic lymphoma U937 cells. Toxicol in vitro 2011;25:1687-1693.

18 Braun L, Cohen M. Herbs \& Natural Supplements, volume 2. Churchill Livingstone Australia; $4^{\text {th }}$ edition, 2015 eBook ISBN: 9780729581738.

19 Cui Z-G, Kondo T, Matsumoto H: Enhancement of apoptosis by nitric oxide released from alpha-phenyl-tertbutyl nitrone under hyperthermic conditions. J Cell Physiol 2006;206:468-476.

20 Grootaert C, Gonzales GB, Vissenaekens H, Wiele T Van De, Raes K, Smagghe G, Camp J Van: Flow cytometric method for the detection of flavonoids in cell lines. J Biomol Screen 2016;21:858-865.

21 Sellins KS, Cohen JJ: Gene induction by gamma-irradiation leads to DNA fragmentation in lymphocytes. J Immunol 1987;139:3199-3206.

22 Zhao QL, Fujiwara Y, Kondo T: Mechanism of cell death induction by nitroxide and hyperthermia. Free Radic Biol Med 2006; DOI: 10.1016/j.freeradbiomed.2005.10.064.

23 Hertveldt K, Philippé J, Thierens H, Cornelissen M, Vral A, De Ridder L: Flow cytometry as a quantitative and sensitive method to evaluate low dose radiation induced apoptosis in vitro in human peripheral blood lymphocytes. Int J Radiat Biol 1997;71:429-433.

24 Huang Y, Hu J, Zheng J, Li J, Wei T, Zheng Z, Chen W: Down-regulation of the PI3K/Akt signaling pathway and induction of apoptosis in CA46 Burkitt lymphoma cells by baicalin. J Exp Clin Cancer Res 2012;31:48.

25 Lu H-F, Hsueh S-C, Ho Y-T, Kao M-C, Yang J-S, Chiu T-H, Huamg S-Y, Lin C-C, Chung J-G: ROS mediates baicalin-induced apoptosis in human promyelocytic leukemia HL-60 cells through the expression of the Gadd153 and mitochondrial-dependent pathway. Anticancer Res 2007;27:117-125.

-26 Chernorudskiy AL, Zito E: Regulation of calcium homeostasis by ER redox: A close-up of the ER/ mitochondria connection. Elsevier Ltd, 2017. DOI: 10.1016/j.jmb.2017.01.017.

27 Tripathi P, Hildeman D: Sensitization of T cells to apoptosis-a role for ROS? Apoptosis 2004;9:515-523.

28 Mantso T, Goussetis G, Franco R, Botaitis S, Pappa A, Panayiotidis M: Effects of hyperthermia as a mitigation strategy in DNA damage-based cancer therapies. Semin Cancer Biol 2016;37-38:96-105.

29 Fu S, Xu L, Li S, Qiu Y, Liu Y, Wu Z, Ye C, Hou Y, Hu C-A: Baicalin suppresses NLRP3 inflammasome and nuclear factor-kappa B (NF-кB) signaling during Haemophilus parasuis infection. Vet Res 2016;47:80. DOI 10.1186/s13567-016-0359-4.

-30 Darling NJ, Cook SJ: The role of MAPK signalling pathways in the response to endoplasmic reticulum stress. Biochim Biophys Acta 2014;1843:2150-2163. 


\section{Cellular Physiology Cell Physiol Biochem 2018;45:2444-2460 \begin{tabular}{l|l} 
and Biochemistry DOI: 10.1159/000488263 & $\begin{array}{l}\text { C) 2018 The Author(s). Published by S. Karger AG, Basel } \\
\text { www.karger.com/cpb }\end{array}$
\end{tabular}

-31 Lin C, Tsai S-C, Tseng MT, Peng S-F, Kuo S-C, Lin M-W, Hsu Y-M, Lee M-R, Amagaya S, Huang W-W, Wu T-S, Yang J-S: AKT serine/threonine protein kinase modulates baicalin-triggered autophagy in human bladder cancer T24 cells. Int J Oncol 2013;42:993-1000.

-32 Budhraja A, Gao N, Zhang Z, Son YO, Cheng S, Wang X, Ding S, Hitron A, Chen G, Luo J, Shi X: Apigenin induces apoptosis in human leukemia cells and exhibits anti-leukemic activity in vivo. Mol Cancer Ther 2012;11:132-142.

-33 Wang X-Y, Zhang X-H, Peng L, Liu Z, Yang Y-X, He Z-X, Dang H-W, Zhou S-F: Bardoxolone methyl (CDDO-Me or RTA402) induces cell cycle arrest, apoptosis and autophagy via PI3K/Akt/mTOR and p38 MAPK/Erk1/2 signaling pathways in K562 cells. Am J Transl Res 2017;9:4652-4672.

-34 Gao N, Budhraja A, Cheng S, Liu E-H, Chen J, Yang Z, Chen D, Zhang Z, Shi X: Phenethyl isothiocyanate exhibits antileukemic activity in vitro and in vivo by inactivation of Akt and activation of JNK pathways. Cell Death Dis 2011;2:e140 DOI:10.1038/cddis.2011.22.

35 Mah LY, Ryan KM: Autophagy and cancer. Cold Spring Harb Perspect Biol 2012;4:1-14.

-36 Chen J, Crawford R, Xiao Y: Vertical inhibition of the PI3K/Akt/mTOR pathway for the treatment of osteoarthritis. J Cell Biochem 2013;114:245-249.

37 Mizushima N: The role of the Atg1/ULK1 complex in autophagy regulation. Curr Opin Cell Biol 2010;22:132-139.

38 Jones EL, Oleson JR, Prosnitz LR, Samulski T V., Vujaskovic Z, Yu D, Sanders LL, Dewhrist MW: Randomized trial of hyperthermia and radiation for superficial tumors. J Clin Oncol 2005;23:3079-3085.

39 Lin Y, Liu Z, Li Y, Liao X, Liao S, Cen S, Yang L, Wei J, Hu X: Short-term hyperthermia promotes the sensitivity of MCF-7 human breast cancer cells to paclitaxel. Biol Pharm Bull 2012;36:1-20.

40 Chan FL, Choi HL, Chen ZY: Induction of apoptosis in prostate cancer cell lines by a flavonoid, baicalin. Cancer Lett 2000;160:219-228.

-41 He Z, Li B, Rankin GO, Rojanasakul Y, Chen YC: Selecting bioactive phenolic compounds as potential agents to inhibit proliferation and VEGF expression in human ovarian cancer cells. Oncol Lett 2015;9:1444-1450.

-42 Martínez Medina JJ, Naso LG, Pérez AL, Rizzi A, Ferrer EG, Williams PAM: Antioxidant and anticancer effects and bioavailability studies of the flavonoid baicalin and its oxidovanadium(IV) complex. J Inorg Biochem 2017;166:150-161.

43 Yano H, Mizoguchi A, Fukuda K, Haramaki M, Ogasawara S, Momosaki S, Kojiro M: The herbal medicine sho-saiko-to inhibits proliferation of cancer cell lines by inducing apoptosis and arrest at the G0/G1 phase. Cancer Res 1994;54:448-454.

44 Douglas R. Green JCR: Apoptosis: Physiology and Pathology. ed 1 cambridge university press, 2011 Available from: ttps://www.abebooks.com/servlet/BookDetailsPL?bi=11793696202\&searchurl=sts\%3Dt \%26sortby\%3D17\%26tn\%3Dapoptosis\%26isbn\%3D9780521886567\%26kn\%3Dapoptosis\%26an\%3Dr eed.

45 Wolf BB, Schuler M, Echeverri F, Green DR: Caspase-3 is the primary activator of apoptotic DNA fragmentation via DNA fragmentation factor-45/inhibitor of caspase-activated DNase inactivation. J Biol Chem 1999;274:30651-30656.

-46 Raza MH, Siraj S, Arshad A, Waheed U, Aldakheel F, Alduraywish S, Arshad M: ROS-modulated therapeutic approaches in cancer treatment. J Cancer Res Clin Oncol 2017;143:1789-1809.

47 Chang W-S, Lin E-Y, Hsu S-W, Hu P-S, Chuang C-L, Liao C-H, Fu C-K, Su C-H, Gong C-L, Hsiao C-L, Bau D-T, Tsai $\mathrm{C}-\mathrm{W}$ : Baicalin scavenged reactive oxygen species and protected human keratinocytes against UVB-induced cytotoxicity. In vivo 2016;30:605-610.

48 Lv F, Yu Y, Zhang B, Liang D, Li ZM, You W: Inhibitory effects of mild hyperthermia plus docetaxel therapy on ER (+/-) breast cancer cells and action mechanisms. J Huazhong Univ Sci Technol-Med Sci 2013;33:870876.

49 Wada T, Penninger JM: Mitogen-activated protein kinases in apoptosis regulation. Oncogene 2004;23:2838-2849.

50 Gaitanaki C, Mastri M, Aggeli I-KS, Beis I: Differential roles of p38-MAPK and JNKs in mediating early protection or apoptosis in the hyperthermic perfused amphibian heart. J Exp Biol 2008;211:2524-2532.

51 Yung H-W, Alnæs-Katjavivi P, Jones CJP, El-Bacha T, Golic M, Staff A-C, Burton G-J: Placental endoplasmic reticulum stress in gestational diabetes: the potential for therapeutic intervention with chemical chaperones and antioxidants. Diabetologia 2016;59:2240-2250. 


\section{Cellular Physiology Cell Physiol Biochem 2018;45:2444-2460 \begin{tabular}{l|l} 
DOI: 10.1159/000488263 & $\begin{array}{l}\text { O 2018 The Author(s). Published by S. Karger AG, Basel } \\
\text { www.karger.com/cpb }\end{array}$ \\
\hline
\end{tabular}

52 Benbrook DM, Masamha CP: The pro-survival function of Akt kinase can be overridden or altered to contribute to induction of apoptosis. Curr Cancer Drug Targets 2011;11:586-599.

53 Zhang Y, Fu R, Liu Y, Li J, Zhang H, Hu X, Chen Y, Liu X, Li Y, Li P, Liu E, Gao N: Dephosphorylation and mitochondrial translocation of cofilin sensitizes human leukemia cells to cerulenin-induced apoptosis via the ROCK1/Akt/JNK signaling pathway. Oncotarget 2016;7:20655-20668.

54 Kim AH, Khursigara G, Sun X, Franke TF, Chao M V: Akt Phosphorylates and Negatively Regulates Apoptosis Signal-Regulating Kinase 1. Mol Cell Biol 2001;21:893-901.

-55 Park S, Lim W, Bazer FW, Song G: Naringenin induces mitochondria-mediated apoptosis and endoplasmic reticulum stress by regulating MAPK and AKT signal transduction pathways in endometriosis cells. Mol Hum Reprod 2017;23:842-854.

56 Jiang L-L, Sun B-R, Zheng C, Yang G-L: The antitumour effects of eudesmin on lung cancer by inducing apoptosis via mitochondria-mediated pathway in the tumour cells. Pharm Biol 2017;55:2259-2263.

57 Araki T, Hayashi M, Watanabe N, Kanuka H, Yoshino J, Miura M, Saruta T: Down-regulation of Mcl-1 by inhibition of the PI3-K/Akt pathway is required for cell shrinkage-dependent cell death. Biochem Biophys Res Commun 2002;290:1275-1281.

58 Wang C-H, Tsai T-F, Wei Y-H: Role of mitochondrial dysfunction and dysregulation of Ca (2+) homeostasis in insulin insensitivity of mammalian cells. Ann N Y Acad Sci 2015;1350:66-76.

59 Lee J-H, Li Y-C, Ip S-W, Hsu S-C, Chang N-W, Tang N-Y, Yu C-S, Chou S-T, Lin S-S, Lin C-C, Yang J-S, Chung J-G: The role of Ca2+ in baicalein-induced apoptosis in human breast MDA-MB-231 cancer cells through mitochondria- and caspase-3-dependent pathway. Anticancer Res 2008;28:1701-1711. 